\title{
PORTAL MUSEU DA EDUCAÇÃO DO DISTRITO FEDERAL E A ORGANIZAÇÃO DO SEU ACERVO EM SUPORTES TECNOLÓGICOS E VIRTUAIS
}

\author{
Maria Paula Vasconcelos Taunay'
}

\author{
Resumo \\ Este artigo visa narrar o trabalho de \\ pesquisa realizado para a criação e \\ implementação do portal Museu da \\ Educação do Distrito Federal (Por- \\ tal MUDE), valendo-se de uma visão \\ multidisciplinar. \\ Palavras-chave \\ Museu da Educação, Portal, Digitaliza- \\ ção,Acervo.
}

\begin{abstract}
This article aims to narrate the research work carried out for the creation and implementation of the portal of the Museum of Education of the Federal District (Portal MUDE) with a multidisciplinary approach.

Keywords

Museu of Education, Website, Scanning, collection
\end{abstract}

O presente artigo relata o desenvolvimento do trabalho de pesquisa realizado para a criação e implantação do portal Museu da Educação do Distrito Federal. Originado do desejo de evocar experiências educativas e históricas na rede pública de ensino, este trabalho pretende ampliar e divulgar o acervo temático do Museu da Educação e viabilizar a democratização do acesso ao conhecimento constituído pela história da educação local. Espera-se que a população do Distrito Federal interaja no referido portal e que seus conteúdos produzidos nos primórdios da educação despertem o seu interesse a preservação dessas memórias.

\footnotetext{
A proposição recorre corrente da história cultural cujos princípios conceituais e metodológicos permitem interpretar a realidade do passado por meio de suas representações, na tentativa de chegar às formas discursivas e imagéticas pelas quais os homens expressam a si próprios e o mundo (Halbwachs, 1990:54).
}

Objeto de pesquisa em educação, o estudo da sua memória em Brasília desenvolve-se há quinze anos, no âmbito da Faculdade de Educação da Universidade de Brasília, em frentes de investigações de onde resulta a constituição de acervo temático e de produções acadêmicas. As pesquisas: "Educação Básica Pública no Distrito Federal (1956-1964): origens de um projeto inovador" e "Educação Básica Pública no Distrito Federal (1964-|97|): desmonte de um projeto inovador", integrantes do grupo de pesquisa HISTEDBR-DF, credenciado junto ao $\mathrm{CNPq}$, são referências regionalizadas destes estudos. A partir da busca por documentos em arquivos públicos e privados e do uso de meios próprios à história oral, acumula-se em suportes audiovisuais registros de mais

I Possui graduação em Pedagogia pelo Centro Universitário de Brasília (I 992). É Especialista em Educação a Distância pela Universidade Católica de Brasilia - UCB (200I). É Mestra em Educação e Mídias pela Universidade de Brasilia - UnB e Doutora na mesma Universidade. 
de 300 depoimentos de professores, gestores e estudantes bem como documentos, fotografias e objetos escolares, referentes ao período 1956- I97I. Para consolidação deste acervo foram acolhidas doações de pessoas físicas e jurídicas, assim como de pesquisas oriundas de artigos, monografias, dissertações, teses e livros, além dos registros de eventos como seminários, rodas de memória e palestras.

A coleta de dados relativa aos primórdios do sistema educacional no Distrito Federal buscou dados a respeito de sua criação, sob embasamento teórico do pensador Anísio Teixeira, em instituições de ensino, majoritariamente, localizadas no Plano Piloto. Procurou-se ainda informações sobre seus gestores, professores e estudantes pioneiros para diversificar entre atos, acontecimentos e lembranças o aprendizado social.

A presente pesquisa pressupõe que estes conhecimentos, quando fornecidos como um conjunto de conhecimentos culturais, científicos e históricos, fortalecem os laços culturais e sociais entre os professores e agrega valor à sociedade brasileira de modo geral. Para a equipe idealizadora do portal, tratava-se da criação de uma referência virtual na cultura educacional local, com possibilidades concretas para o fomento às novas pesquisas e para a veiculação das produções educativas destinadas à sua comunidade escolar e, prioritariamente, para os antigos e atuais professores, estudantes, funcionários, gestores da rede pública de ensino, e, em uma escala estendida, toda a sociedade escolarizada do Distrito Federal.

Tendo em vista o estado de dispersão dos conteúdos relacionados ao tema, formulou-se esta proposta para reunir, classificar e qualificar este acervo, tarefa de proporções desafiadoras que indicava a necessidade da adoção do uso de tecnologias de ponta para otimizar a demanda de tratamento e difusão do acervo. Acreditava-se que $\circ$ alinhamento de linguagens pedagógicas históricas ao uso de ferramentas tecnológicas permitiria a localização e identificação dos personagens de memórias educativas bem como a obtenção de novos dados de pesquisa potencializados por meio de coleta e interação virtual.

A constituição do acervo formulado como arquivo, biblioteca e museu demandou habilidade técnica, administrativa e operacional de equipe multidisciplinar empenhada em produzir e relatar a experiência do processo constitutivo, formativo, de tratamento e organização deste valioso acervo. Assim, idealizou-se um sistema digital voltado aos públicos-alvo do Museu da Educação elaborado por equipe multidisciplinar constituída por professores e estudantes da Educação, História, Arquivologia, Ciência da Informática e Museologia atentos às inovações tecnológicas e abertos ao debate em torno das concepções educacionais, culturais e patrimoniais.

\section{Tratamento das memórias educativas, uma experiência pedagógica}

Com a composição do acervo do Museu e suas fontes documentais de pesquisas em acervos públicos e privados, teve início o processo de recuperação das referências históricas e da memória individual e coletiva da educação básica pública do Distrito Federal.A equipe preparava-se para dar continuidade ao tratamento e preservação do acervo conforme pesquisas a respeito do patrimônio educacional no Brasil e no mundo. Com vistas a adequar linguagens 
Portal Museu da Educação do DFe a organização do seu acervo em suportes tecnológicos e virtuais

disponíveis para sua comunicação, analisava-se recursos capazes de informar a sociedade para a relevância das suas publicações, exposições e outros eventos relacionados à história e identidade.

os arquivos precisam corresponder ao interesse da História em busca de suas fontes. Na medida em que venha a se organizar, estarão permitindo, e até motivando a pesquisa e produção histórica. (Esposel, 1994: 195).

A relação intrínseca da história com arquivos repercute na sociedade e a desafia a estruturar e sistematizar uma cultura educativa baseada em fontes documentais. Estas fontes, materialmente diversificadas, estão preservadas em fontes textuais impressas, audiovisuais como vídeos e fitas cassete, iconográficas em fotografias, quadros, cartazes, postais, informáticas em CD's, DVD's, mini-DVD's e em outras tipologias de documentos manuscritos, datilografados das escolas pioneiras. São manuscritos das escolas pioneiras, planos de ensino, publicações escolares, relatórios, atas, correspondências expedidas e recebidas, dados demográficos e estatísticas escolares que ressaltam a importância da história e dos arquivos.

Os arquivos públicos existem com a função precípua de recolher, custodiar, preservar e organizar fundos documentais originados na área governamental, transferindo-lhes as informações para servir ao administrador, ao cidadão e ao historiador [...]. [...] no entanto, para além dessa competência que justifica e alimenta sua criação e desenvolvimento, cumpre-lhe ainda uma atividade que, embora secundária, é a que melhor pode desenhar os seus contornos sociais, dando-lhe projeção na comunidade, trazendo-lhe a necessária dimensão popular e cultural, que reforça e mantém o seu objetivo primeiro. Trata-se de seus serviços editoriais, de difusão cultural e de assistência educativa (Belloto, 1991: 147).

Constituído o Fundo arquivístico denominado "Memória da Educação Básica Pública do Distrito Federal" (MEBP-DF) - com foco no Sistema Educacional do Distrito Federal e em seus aspectos culturais, administrativos e científicos -, surgia a necessidade de sistematização documental conforme sua "criação, avaliação, aquisição, conservação, classificação, descrição e difusão dos arquivos [...]” (Rousseau; Couture, 1998: 265).

Durante a fase de diagnóstico do acervo, criaram-se instrumentos de gestão como o plano de classificação de documentos, o índice remissivo alfabético e a tabela de temporalidade. Posteriormente, foi elaborado o inventário de documentos textuais, o inventário de documentos fotográficos, o catálogo de eventos, o quadro de arranjo e as listagens auxiliares de professores, gestores, alunos e da planilha de controle das entrevistas gravadas, filmadas e editadas no programa de depoimentos de história oral. Então, estabeleceu-se a seguinte cronologia das atividades operacionais de tratamento do acervo: 
0. Identificação do acervo, mensuração dos documentos, sistematização de assuntos e temas;

a. Classificação dos temas conforme os instrumentos de gestão documental: plano de classificação de documentos, tabela de temporalidade, índice remissivo alfabético;

b. Acondicionamento dos documentos classificados: com uso de EPI's (equipamentos de proteção individual, as luvas, máscaras), camisas protetoras para os documentos, pastas suspensas e caixas-arquivo comum e especiais para as fotografias;

c. Armazenamento em estantes de aço e armários especiais para fotografias;

d. Digitalização e cadastro dos documentos textuais, fotográficos e peças museais no Sistema Arquivístico do Museu da Educação, SAMUDE;

e. Produção do inventário sumário de documentos textuais e de fotografias, do catálogo de eventos e do quadro de arranjo;

f. Produção de instrumentos auxiliares como listagens de gestores e professores pioneiros, glossário arquivístico, e um manual de procedimentos arquivísticos.

A tabela de temporalidade de documentos, instrumento de gestão documental e a avaliação de documentos, resultou de processo legal respaldado pelo Museu da Educação enquanto órgão detentor dos documentos e por comissão especializada na função. Respaldada na concepção do Plano de Classificação de Documentos do Museu, aplicava a teoria das três idades e a noção de ciclo vital dos documentos; dos prazos prescricionais de decadência e vigência e da seleção dos documentos em prazos de guarda determinados em lei; da aplicação de critérios da valoração de documentos segundo valores primários e secundários dos documentos; do uso da destinação final do documento (eliminação ou guarda permanente) e da indicação de critérios de reprodução em microfilmagem e/ ou digitalização de documentos para preservação como referências técnicas ao trabalho científico. Sua criação facilitou o gerenciamento da produção e destinação da massa documental a ser exposta no portal, indicando os documentos para uso corrente e/ou de caráter histórico. Ainda permitiu recuperar informações e controle sistemático do acesso aos documentos relevantes as pesquisas e estudos.

Após a fase de qualificação do acervo, conforme critérios administrativos, jurídicos, fiscais, técnicos e operacionais, o conteúdo do acervo estava preparado para a etapa de digitalização, ainda como fase preparatória ao desenvolvimento do projeto do portal. A segunda etapa do tratamento arquivístico do acervo selecionado e classificado, foi enviado para digitalização na empresa SQATi, de propriedade de Manoel Matias, responsável pelo tratamento de 18.870 documentos de propriedade da pesquisa, transportados em três remessas e retornados em suportes virtuais em HDs e pen drives. 
Deste universo, uma parcela de dez por cento foi encaminhada para a fase de descrição e classificação, com etapa de distribuição por classes, categorias, segundo a ordem e método propostos por Mendes para o tratamento do acervo. Esta etapa se determina como processo de identificação e reagrupamento sistemático de itens semelhantes, conforme características comuns que podem ser objeto de diferenciação, se a quantidade demandar.

\begin{abstract}
Esta função consiste em um conjunto de convenções, métodos e regras de procedimentos estruturados de forma lógica e permitindo categorizar documentos por categorias ou grupos, independentemente do seu suporte e idade. $O$ objetivo final da classificação é, naturalmente, facilitar a informação contida nos documentos de arquivos e, assim, permitir uma melhor compreensão do contexto de funcionamento de uma pessoa física ou jurídica em causa (Roncaglio e Manini, 2016: p.33).
\end{abstract}

Formulado como um meio de acesso documental, a se enquadrar entre um dos critérios indicados pelo padrão de classificação utilizado para a avaliação de sítios de bibliotecas universitárias brasileiras, o portal começava a ganhar um formato. Durante esta fase de construção coletiva do portal, a equipe do sítio procurou se adequar a atender demandas por interesses informacionais, promocionais, instrucionais, referências, de pesquisa ou de comunicação. No campo virtual, a cumulatividade das funções se adaptam às características das informações fornecidas, uma vez que o portal cumpria amplo espectro de funcionalidades. Neste processo, reconheceu-se que o portal inseriu-se na categoria informacional ao oferecer informações sobre a instituição mantenedora do sítio mas soma-se à categoria referencial ao "linkar" outras fontes de informação existentes no sítio. Com o mesmo propósito, o portal ainda agrega-se como endereço de pesquisa por oferecer serviços e produtos on-line no sítio e à categoria de comunicação, por contar com mecanismos para estabelecer relacionamentos e contatos com a instituição. Enfim, parte-se para o desenvolvimento da principal contribuição científica da proposta, sendo esta o potencial ampliação do acervo em virtude da ampla abertura de canais de comunicação entre os detentores de memórias e os pesquisadores.

Consolidava-se a busca de uma identidade alinhada à do Museu da Educação de forma a reflectir marca e identidade mediante a adoção de logomarca, como perfil adequado a paleta de cores e letras, aprovada por seu potencial de promoção.

Neste processo, adotou-se o domínio "museudaeducacao.com.br" e, posteriormente negociou-se garantias de inserção institucional do portal no endereço eletrônico da Secretaria de Educação do Distrito Federal, do qual também faz parte. Concomitantemente, criava-se produtos tecnológicos de hospedagem na internet enquanto desenvolvia-se software para atender as demandas de interatividade, de aglomeração e distribuição de conteúdo. $\bigcirc$ portal ganhava um motor de busca ao seu acervo e outras funções como o estabelecimento de um diretório de pesquisa e inclusão de dados no banco de imagens, documentos e mídias. 
desenvolvimento dos conteúdos destinados a alimentar as abas do portal e a seleção de materiais visuais e gráficos foi processado num formato estético pré-estabelecido em um menu fixo com abas móveis, imagens em movimento e álbuns de fotos. Em comum acordo, a equipe do Museu da Educação determinou o destaque dos temas como Educação no Museu, Educação Patrimonial, Educação Ambiental e Interatividades. Sugeriu-se, igualmente, a elaboração dos álbuns de fotos expos ao usuário a possibilidade de identificação de personagens e dados, ampliando-se ainda mais as perspectivas da pesquisa para novos personagens, em novas temporalidades e territorialidades da memória educativa.

Enquanto equipe multidisciplinar, os participantes da criação do portal receberam treinamento especializado para dar tratamento virtual aos documentos históricos, trabalho desenvolvido após a digitalização dos documentos históricos. A tarefa demandava sua descrição e indexação conforme o Plano de Classificação do Museu da Educação bem como para a manipulação dos produtos inerentes ao acervo na inserção, descrição e manipulação de informações neste banco de dados.

\begin{abstract}
A descrição é uma função arquivística central intimamente relacionada à classificação. Esta função é regida por três princípios básicos. Quando escreve, o arquivista deve: observar o princípio de respeito aos fundos; refletir os níveis de classificação; e proceder do geral para o particular. A descrição deve: respeitar o fundo de arquivo, pois este é a unidade básica de qualquer operação de arquivo; refletir os níveis de classificação que são: os centros de arquivos, os fundos, as séries, o dossiê e o item documental, uma vez que estes refletem com mais precisão e detalhes das funções e as atividades da pessoa física ou jurídica que é produtora do fundo.(...) A descrição consiste em" condensar, categorizar, agrupar e organizar as informações contidas em uma ampla variedade de documentos e em uma grande variedade de suportes, expressas de maneira bastante variada (Couture apud Roncaglio; Manini, 2016: 34).
\end{abstract}

Uma das mais relevantes ações multidisciplinares partiu do desenvolvimento do sistema SAMUDE iniciado em julho de 2014 com o convite ao analista de sistemas Luiz Osório Antunes para se integrar à equipe da pesquisa do Museu da Educação do Distrito Federal. $O$ convite deu-se devido à sua experiência como responsável pelo desenvolvimento do sistema Digifotoweb para - Arquivo Central (ACE) da UnB, sob orientação do professor André Porto Ancona Lopez, da Faculdade de Ciência da Informação, cujo objetivo era idêntico. Atualmente o SAMUDE encontra-se em fase de classificação, contando com 669 fotografias, 14 entrevistas e 1.200 documentos textuais resultantes de um acervo com 14 metros lineares de documentos textuais, 2.500 documentos iconográficos e aproximadamente 200 entrevistas em áudio e vídeo disponibilizados em acervo fotográfico do ACE na Internet.

Com o propósito de abrigar o acervo digitalizado do Museu da Educação, - SAMUDE desenvolveu-se a partir de um software livre, ou seja, de um sistema gerenciador de banco de dados relacional Postgresql, framework de de- 
Portal Museu da Educação do DFe a organização do seu acervo em suportes tecnológicos e virtuais

senvolvimento web Ruby on Rails, computador com sistema operacional Linux Ubuntu Server e servidor web Nginx. A framework Ruby on Rails (www.http:// rubyonrails.org/) é uma ferramenta de programação para sistemas web bastante madura e difundida, sendo adotada por inúmeras empresas no mundo todo. Um dos seus principais lemas é "Convention Over Configuration", ou seja, ela adota convenções consagradas pela comunidade de programadores, tomando centenas de decisões automaticamente, sem a necessidade de intervenção humana. Desta forma, torna possível que até um único técnico experiente consiga fazer o trabalho de toda uma equipe que use outras linguagens.

O surgimento recente de novas ferramentas de desenvolvimento de sistemas, fruto da rápida evolução da tecnologia da informação, trouxe a preocupação da obsolescência do software utilizado para criar este sistema foi utilizado o programa Ruby on Rails, mesmo sem garantias de que o programa se perpetue como alternativa viável aos sistemas web, tal como é hoje. Existem exemplos de tecnologias que tiveram sua "idade de ouro" e hoje caíram no esquecimento se esforçam para substituir. Pensando nisso, para preservar o investimento do Museu da Educação do Distrito Federal, que - acredita-se - servirá a muitas gerações futuras, tomou-se a decisão de transferir a maior parte da programação para o sistema gerenciador de banco de dados, cuja tecnologia até agora não se deparou com paradigma capaz de superá-la num horizonte de décadas. Assim, aproximadamente $90 \%$ do código do sistema é escrito em linguagem SQL, Structured Query Language, linguagem universal dos bancos de dados relacionais. O SAMUDE seguiu o clássico ciclo que inicia com entrevistas do analista com os futuros usuários do sistema, segue com o levantamento dos requisitos, o ordenamento das mesmas segundo critérios de prioridade, o preparo de protótipos das funcionalidades requeridas, a exposição dos mesmos para os usuários, a programação do sistema e liberação de versões de produção do software para início e continuidade dos trabalhos de inserção de dados no banco de dados. A citar, o processamento dos documentos fotográficos começou em outubro de 2014 e continua em fase de desenvolvimento. A seguir, o sistema incorporou o processamento dos documentos textuais e das mídias guardias de conteúdos importantes do acervo, cuja inclusão no banco de dados em junho de 2017 e dos objetos museais, em agosto de 2017.

Durante o experimento, cuidou-se de criar recursos de recuperação de informações a partir do acervo catalogado como uma busca textual que contempla diversos campos de interesse dos futuros usuários e pesquisadores. Também merece menção a disponibilização de recursos disponibilizados para revisão dos dados que já inseridos no sistema, de forma a melhorar a qualidade dos registros que descrevem o acervo. Cientes dos recursos computacionais de memória, processador e espaço em disco alocados e seus limites, decidiu-se pela criação de um segundo sistema, o "SAMUDE X", com acesso ao mesmo banco de dados e materiais imagéticos do sistema primário, mas apenas com os recursos de leitura e pesquisa do mesmo. $O$ resultado foi um software menor e menos exigente que o original e, portanto capaz de atender um número maior de consultas pela Internet.

A experiência de criação, desenvolvimento e implantação do portal Museu da Educação do Distrito Federal demandou uma série conhecimentos articulados entre pessoal especializado, técnico, institucional e de base.A conversão 
dos interesses deu-se de maneira articulada permitindo ao portal a transmissão da missão e dos objetivos do Museu da Educação do Distrito Federal. Estas informações dando conhecimento sobre o seu plano museológico, o catálogo de eventos, o inventário e o índice remissivo do acervo mostraram o grau de preparo da referida instituição estruturada não apenas no Plano Educacional do Distrito Federal mas também em diversos aspectos importantes desta proposta e os personagens da educação pública da época, como Anísio Teixeira e os professores pioneiros, entre outras informações.

As funções arquivísticas e suas metodologias foram elementos balizadores e essenciais na condução do processo de sistematização e estruturação na organização do acervo documental do Museu da Educação do Distrito Federal. O trabalho de equipe esforçou-se por aderir às normas dos organismos nacionais de fomento à pesquisa e estudo científico do cenário acadêmico brasileiro para disponibilizar ao público brasileiro e quiçá internacional uma parcela modesta do patrimônio educacional do Sistema Pioneiro da Educação do Distrito Federal.

Espera-se que a publicação do conteúdo do acervo do Museu desperte progressivamente $o$ interesse de acadêmicos e alunos, administradores e cidadãos e do público em geral para e necessidade de resguardar a história, memória, a identidade patrimonial e educacional não só dos pioneiros da educação básica pública do Distrito Federal, mas na formação de cidadãos da educação nacional. Confia-se ainda na continuidade das ações, afinal, em escaninho de professor, sempre há o que fazer e as memórias da educação só tendem a aumentar.

\section{Referências}

ALMEIDA, Cícero Antônio F. de. Organização de projetos em museus. Anotações para o IV Encontro sobre Museu, Preservação de Patrimônio, Memória e Identidade UNIVATES. Lajeado, 17 e 18 de agosto de 2006.

AMARAL, Clara Ramthum;FERREIRA FILHO, Raimundo Mendes. Índice Remissivo Alfabético do Museu da Educação do Distrito Federal. Brasília: MUDE, 2014.

AMARAL, Clara Ramthum \& FERREIRA FILHO, Raimundo Mendes. Inventário Sumário Memória da Educação Básica Pública do Distrito Federal. Brasília: MUDE, Arquivo, 2014.

ARQUIVO NACIONAL (Brasil). Publicações. Disponível em: <www.arquivonacional.gov.br>.Acesso em: |3/07/2016.

BELLOTTO, Heloisa Liberalli. Arquivos Permanentes: tratamento documental. São Paulo:T.A. Queiroz, 1991

ESPOSEL, José Pedro. Arquivos: uma questão de ordem. Niterói:Muiraquitã, 1994.

COSTA, Cláudio; MELO, Joaquim; FABIANO, Luiz (orgs.). Fontes e métodos em história da educação. Dourados: Ed. UFGD, 2010. 
Portal Museu da Educação do DFe a organização do seu acervo em suportes tecnológicos e virtuais

LE GOFF, Jacques. História e Memória. Campinas: Ed. Unicamp, 1994.

HALBWACHS, Maurice. A Memória Coletiva. São Paulo: Editora Vértice, 1999.

MANINI, Miriam Paula; Marques, Otacílio Guedes; MUNIZ, Nancy Campos (orgs.). Imagem, memória e informação. Brasília: Editora Ícone e Gráfica, 2010.

NORA, Pierre; KHOURY, Yara. Entre memória e História: a problemática dos lugares. Projeto História. Revista do Programa de Estudos Pós-Graduados de História. São Paulo, n. 10, dez. 1993. Disponível em: <https://revistas.pucsp.br/index. php/revph/article/view/I210I>.Acesso em: 20/08/2017.

POLLAK, Michael. Memória e identidade social. Revista Estudos Históricos. Rio de Janeiro, v. 5, n. I0, p. 200-215, 1992.

RONCAGLIO, Cynthia; MANINI, Miriam P. Arquivologia e cinema: um olhar arquivístico sobre narrativas fílmicas. Brasília: Editora UnB, 2016.

TAUNAY, Maria Paula Vasconcelos e FERREIRA FILHO, Raimundo Mendes. Catálogo de eventos e publicações do Museu da Educação do Distrito Federal. Brasília: MUDE, 2014.

TEIXEIRA, Anísio. Educação no Brasil. São Paulo: Cia. Editora Nacional, 1969. 